\title{
Onde mora a autonomia do paciente em tempos de crise em Portugal?
}

\author{
Where does patient autonomy live, in times of crisis in Portugal?
}

Ana Filipa Fontes (https://orcid.org/0000-0002-5474-4748) ${ }^{1}$

Rita Ribeiro Barbosa (https://orcid.org/0000-0002-5728-9840) ${ }^{1}$

Dinis Brito (https://orcid.org/0000-0002-7547-0053) ${ }^{2}$

${ }^{1}$ Unidade de Saúde Familiar 7 fontes, ACeS Cávado I. R. Padre António Freire 7/2。 andar. 4700-395 Braga Portugal.

filipafontes@live.com.pt

${ }^{2}$ Instituto de Investigação em Ciências da Vida e

Saúde, Universidade do

Minho. Minho Portugal.

\begin{abstract}
Coronavirus disease 2019 made us question daily practices, such as the simple handshake. It also raised some ethical and legal issues. Are the ethical principles, that should guide the provision of individualized care, being fulfilled? Will we, as health professionals, be able to provide patients with instruments so that they can fully exercise their autonomy? The guarantee of necessary security solutions, to reduce the risk of contagion in the provision of care, safeguards the principle of non-maleficence. However, the risk of contagion is impossible to completely eliminate, and there is a residual risk associated with the use of physical facilities in healthcare services. But, shouldn't the decision to take that risk be the subject of the patient's free and informed will? The incorporation of telemedicine platforms is ideal for managing several challenges posed by COVID-19, such as the decrease in face-to-face health care assistance. Can the patient really decide how he prefers to be consulted, or are we imposing the consultation model? There have been profound changes in healthcare systems. However, one must remember that there are ethical principles of biomedicine, that should always prevail?
\end{abstract}

Key words COVID-19, Telemedicine, Remote consultation, Bioethics, Personal autonomy
Resumo A pandemia de COVID-19 fez-nos questionar práticas diárias até então instituídas, como o simples aperto de mão. Levantou também outras questões, algumas de indole ético-legal. Estarão a ser cumpridos os princípios éticos que devem orientar a prestação de cuidados individualizados? Conseguiremos nós, profissionais de saúde, fornecer instrumentos aos doentes para que possam usufruir plenamente do seu direito de autonomia? A garantia de soluções de segurança necessárias, para diminuir o risco de contágio na prestação de cuidados, salvaguarda o princípio da não maleficiência. Todavia, o risco de contágio é impossivel de eliminar na totalidade, existindo um residual associado à utilização das instalações físicas dos serviços de saúde. Mas, não deverá a decisão de assumir esse risco ser alvo do arbitrio livre, informado e esclarecido do doente? A diminuição da atividade assistencial presencial motivou a incorporação de outras ferramentas de comunicação como telefone, correio eletrónico e videochamada. Poderá o paciente realmente decidir sobre a forma como prefere ser consultado, ou estaremos nós a impor o modelo de consulta? Nos últimos meses ocorreram mudanças profundas na forma de trabalho em Saúde, que permanecerão. Não existirão, contudo, princípios éticos da biomedicina, que deverão sempre prevalecer?

Palavras-chave COVID-19, Telemedicina, Consulta remota, Bioética, Autonomia pessoal 


\section{Artigo de Opinião}

No final da década de 1970, Beauchamp e Childress $^{1}$ descreveram, pela primeira vez, os quatro princípios éticos que devem orientar a prestação de cuidados individualizados. Em 2019 foi publicada a $8^{\text {a }}$ edição deste documento, focando esses princípios, que prima facie são o respeito pela autonomia, beneficência, não maleficência e justiçáa ${ }^{1-3}$.

O princípio do respeito pela autonomia possibilitou a transição de um modelo paternalista para uma medicina centrada na pessoa, que corretamente esclarecida pelo seu médico poderá ponderar e decidir de uma forma livre e responsável pela prestação ou não de determinado cuidado, seja um procedimento diagnóstico ou terapêutico.

A pandemia provocada pelo SARS-COV-2 fez-nos questionar práticas diárias até então instituídas como o simples aperto de mão na receção do doente, tanto pelo risco de contágio, como pela necessidade de distanciamento social, quer por medo dos diversos intervenientes. Muitas das medidas foram tomadas no interesse da saúde pública, delegando para segundo plano os interesses individuais ${ }^{1}$. Assistimos a uma reorganização estrutural ao nível dos Cuidados de Saúde Primários (CSP) e a uma reinvenção do conceito de acessibilidade aos cuidados de saúde. A diminuição da atividade assistencial presencial motivou a incorporação ou a intensificação de outras ferramentas de comunicação como o telefone, o correio eletrónico e, em menor escala, a videochamada. Perante as circunstâncias expostas, onde tem lugar a autonomia de decisão do paciente? Poderá o paciente realmente decidir sobre a forma como prefere ser consultado, ou estaremos nós, profissionais da saúde, a impor o modelo de consulta?

A compartimentação e a sectorização dos cuidados de saúde em Áreas Dedicadas à COVID-19 (ADC) e áreas dedicadas a patologias "não COVID-19", espelha um investimento na saúde comunitária. No entanto, tem-se procurado, também, garantir alternativas que procurem manter o seguimento longitudinal dos doentes, com base numa estratificação por necessidade de cuidado, bem como trabalhar em formas eficazes de literacia em saúde.

De facto, a pandemia abre novas oportunidades de evolução na relação médico-doente. A necessidade de otimizar os contactos com o cidadão, bem como de potenciar a capacidade de autogestão dos seus problemas mórbidos, expo- nencia o fulcro da autonomia do doente. Neste contexto, o médico surge como facilitador de um processo através do qual se estabelece, de forma simples e clara, a forma como os cuidados necessários são prestados integrando o papel do doente e o suporte da sua família. Este Plano Individualizado e Integrado de Cuidados assume-se, portanto, como um processo convergente entre os objectivos de cuidar e a melhor forma de os poder alcançar conhecendo-se os intervenientes e as metas. Este processo permite potenciar a gestão de recursos levando a que cada contacto com o cidadão seja sublimado e alavancado na sua autonomia ${ }^{4,5}$. O utente poderá optar, desde que devidamente esclarecido e informado, pelo atendimento mais adequado às suas circunstâncias, presencial ou não, sem prejuízo do suprimento das necessidades dos outros utentes. Assim será consolidado, portanto, outros dos princípios fundamentais normativos de ação da Biomedicina - a justiça. Será, deste modo, salvaguardada a equidade no nosso sistema de saúde, globalizando o direito de acesso aos cuidados prestados, contemplando ainda o interesse individual. Urge, portanto, fornecer ao paciente, instrumentos para que possa usufruir em pleno do seu direito de autonomia, colocando ênfase nas medidas de proteção individual e coletiva. Por outro lado, importa também a proteção dos profissionais de saúde, porque sem estes, não será possível a prestação de qualquer tipo de cuidados. Ao minimizarmos os focos de contágio no atendimento presencial, estaremos a maximizar a possibilidade prática da não maleficiência, em aceder aos CSP, isto é, a garantia de soluções de segurança necessárias para diminuir o risco de contágio associado à prestação de cuidados salvaguarda $\mathrm{o}$ princípio da não maleficiência. Poder-se-á dizer que o risco de contágio é impossível de eliminiar e que existe um risco residual na utilização das instalações físicas dos serviços de saúde. Contudo, tal em como em qualquer outro procedimento, a decisão de assumir esse risco deve ser alvo do arbítrio livre, informado e esclarecido do doente, respeitando a sua decisão partilhada.

Estreitamente relacionado com o exercício da autonomia, encontra-se o direito à privacidade individual. Embora tido como um dos mais tradicionais princípios morais da assistência em saúde, o sigilo é ainda um dos menos respeitados $^{6}$. Segundo o Conselho Nacional de Ética para as Ciências da Vida, devem ser tidas em conta quatro dimensões diferentes da privacidade: física, mental, decisional e informacional ${ }^{7}$. Apesar da obrigatoriedade do sigilo abranger todos os 
profissionais de saúde, facilmente se depreende, através do direito às duas últimas dimensões citadas (privacidade decisional e informacional), que o doente possa escolher a quem quer confiar informação sobre o seu estado de saúde. Relativamente aos direitos dos utentes, para além do direito ao sigilo sobre os seus dados pessoais nos serviços de saúde, há que realçar o direito de escolha $^{8}$. Escolha de serviços, de prestadores, de querer transmitir a noção sobre o seu estado de saúde, sinais e sintomas de doença, apenas ao seu médico de família. Com a evolução da Pandemia COVID-19 sentiu-se a necessidade de criar algum tipo de triagem à chegada dos doentes. Estarão asseguradas as condições previamente citadas, nos sistemas de triagem montados à entrada das unidades de cuidados (Unidade de Saúde Familiar, Unidade de Cuidados de Saúde Personalizados, ADC)? Numa altura em que muitos secretários clínicos e enfermeiros participam na triagem dos sintomas cardinais de doença, no contexto da Pandemia COVID-19, estará assegurada esta vertente do respeito pela autonomia do utente? $\mathrm{E}$ se não quiser partilhar estes dados com os profissionais na triagem, poderá negar-se o seu acesso aos cuidados de saúde? Deveria esta ser uma triagem especializada/médica/clínica? Urge, portanto, refletir sobre estes pontos e procurar soluções que preservem a autonomia do paciente e a sua confidencialidade, considerando os condicionalismos existentes. Pois mesmo num contexto de calamidade há princípios que se mantêm como fundações de uma boa prática.

Segundo o $29^{\circ}$ artigo do Capítulo IV, do Código Deontológico Médico, o segredo médico é condição essencial ao relacionamento médicodoente. O segredo médico impõe-se em todas as circunstâncias, dado que resulta de um direito alienável de todos os doentes.

Em várias unidades de saúde, ao longo do país, foram colocadas nas últimas semanas, na sala de espera, ou mesmo à entrada dos edifícios, caixas onde os doentes poderiam deixar os seus resultados de meios complementares de diagnóstico e terapêutica. Esta solução encontrada para evitar o contacto com os profissionais de saúde e outros utentes, minimizando os riscos de contágio, parecia interessante. Contudo, mais uma vez se levanta a questão: estará assegurada a confidencialidade (ainda que a decisão de deixar lá os resultados seja do doente)?

$\mathrm{O}$ perigo da quebra de confidencialidade está também presente nos encontros clínicos por via telefónica. Quem estará do outro lado? E se não for o doente que se pensa ser? Na teleconsulta deve valorizar-se a possibilidade de videochamada, para visualização mútua do utente e profissional em causa ${ }^{9}$. A instalação do software necessário para a realização destas consultas é já uma realidade, em muitas unidades prestadoras de cuidados. A Telemedicina é considerada por muitos como o futuro da medicina ${ }^{10}$. Agora, em tempos de confinamento, quando a liberdade e a capacidade de agir dos doentes estão condicionadas, a telemedicina poderá ser uma ajuda valiosa, para ultrapassar esta limitação e providenciar acesso aos cuidados de saúde. Assim, esta nova tendência é já o foco do capítulo VII, do Código Deontológico Médico ${ }^{11}$. No artigo $46^{\circ}$ deste capítulo, define-se que a telemedicina deve respeitar a relação médico-doente, mantendo a confiança mútua, a independência de opinião do médico, a autonomia do doente e a confidencialidade. Segundo o artigo $47^{\circ}$, o médico deve assegurar-se que a formação e a competência dos colaboradores não médicos, participantes na transmissão ou receção de dados, sejam adequadas, de modo a poder garantir uma utilização apropriada da telemedicina e a salvaguarda do segredo médico.

Fica também explícito no $48^{\circ}$ artigo, que o médico só deve utilizar a telemedicina depois de se certificar que o sistema utilizado e os seus utilizadores garantem o segredo médico, nomeadamente, através da encriptação de nomes e outros dados identificadores. Estarão as plataformas colocadas à disposição do médico de família para teleconsulta e seguimento dos doentes (por exemplo o Trace COVID-19, recentemente criado para vigilância de doentes afetados pela Pandemia) adequadas a estas condições?

A abordagem dos cuidados centrados na pessoa inclui os valores, preferências, desejos e necessidades dos pacientes. Será fulcral neste diálogo entender como se sente o paciente, face às diferentes opções de comunicação disponíveis, nas circunstâncias atuais, de forma a promover a sua satisfação e bem estar. Importa também procurar entender como estarão os profissionais de saúde a adaptar-se a esta nova realidade. Nos últimos meses, pautados pela exigência e necessidade de adaptação constantes, ocorreram mudanças profundas nos hábitos e formas de trabalho destes profissionais. Muitas destas alterações vieram para ficar. Há, contudo, princípios como do respeito pela autonomia e confidencialidade do doente, não maleficiência, beneficiência e justiça, que, atendendo ao seu caráter ético-legal na prática da medicina, deverão sempre prevalecer. 


\section{Colaboradores}

Todos os autores contribuíram substancialmente para a realização do artigo. AF Fontes, RR Barbosa e D Brito efetuaram contribuições para a conceção e delineamento do artigo, tendo participado na redação e revisão crítica do artigo, no que respeita a conteúdo intelectualmente importante.

\section{Agradecimentos}

Gostaríamos de agradecer o apoio científico prestado por John Yaphe MD MCISc, Universidade do Minho.

\section{Referências}

1. Bakker M, Van de Vathorst S. Ethical Principles Compromised During the COVID-19 Pandemic? Ned Tijdschr Geneeskd 2020; 164:D5049.

2. Gillon R. Medical ethics: four principles plus attention to scope. BMJ 1994; 309(6948):184-188.

3. Beauchamp TL, Childress JF. Principles of Biomedical Ethics. $8^{\text {th }}$ ed. Oxford: Oxford; 2019.

4. Carneiro R, Simões C, Carneiro AH. Individual and Integrated Care Plan in Clinical Relation. Medicina Interna 2019; 26(2):147-153.

5. Sociedad Española de Medicina de Familia y Comunitaria (SemFYC). OPORTUNIDADES Y AMENAZAS para la prevención y promoción de la salud y el PAPPS en el contexto de la pandemia COVID-19. Madrid: FYC; 2020.

6. Vilas-Boas MA. O direito-dever de sigilo na proteção ao paciente. Rev. bioét. 2015; 23(3):513-523.

7. Bessa MRR. A densificação dos princípios da bioética em Portugal Estudo de caso: a atuação do CNECV [tese]. Porto: Universidade do Porto; 2013.

8. Lei n. ${ }^{\circ} 15 / 2014$. Apresenta de forma clara e integrada os direitos e deveres do utente dos serviços de saúde. Diário da República 2014; 21 mar.

9. Sokol D, Car J. Protecting patient confidentiality in telephone consultations in general practice. $\mathrm{Br} \mathrm{J} \mathrm{Gen}$ Pract 2006; 56(526):384-385.

10. Downes MJ, Mervin MC, Byrnes JM, Scuffham PA. Telephone consultations for general practice: a systematic review. Systematic Reviews 2017; 6:128.

11. Ordem dos Médicos. Regulamento n. ${ }^{\circ}$ 707/2016: Regulamento de Deontologia Médica. Diário da República 2016; 21 jul.

Artigo apresentado em 21/07/2020

Aprovado em 31/07/2020

Versão final apresentada em 02/08/2020 